\title{
A focus on time-lapse ethnography: learning to teach
}

Ethnography and Education

Alaster Scott Douglas

School of Education, University of Roehampton, London, UK

Email: alaster.douglas@ roehampton.ac.uk

Postal Address:

Room E002

Cedar Building

Froebel College

School of Education

University of Roehampton

Roehampton Lane

London SW15 5PJ

UK

ORCID iD: 0000-0003-0972-4315 


\title{
A focus on time-lapse ethnography: learning to teach
}

\begin{abstract}
This article makes the claim that developing ethnographic work through follow up interviews can add to our understanding of researched phenomena and explores how using concepts from Bourdieu and theories on the social construction of time strengthen the research design and add a stronger longitudinal diachronic element to data analysis. Extending an ethnographic study of learning to teach by interviewing respondents nine years after the study and after the completion of their teacher education course is shown to develop insights around the initial research findings by focusing on the temporal aspects of data. Adopting this methodological approach can develop small-scale qualitative work and contribute to an accumulation of research findings to avoid simply revisiting familiar research ground.
\end{abstract}

Key words: longitudinal ethnography, social construction of time, learning to teach, capital

\section{Introduction}

In 2011 I wrote an article for this journal about an ethnographic study which researched the learning opportunities for pre-service teachers when learning on the job as they participated in their first school teaching practice (Douglas 2011). I worked as a researcher in the school for a school year interviewing, observing and analysing the documentation relating to all aspects of pre-service teacher education in the school. The article promoted the benefits of a socio-cultural approach to data analysis and used an analytic framework which was informed by cultural historical activity theory (CHAT) to analyse pre-service teachers' learning opportunities in the school setting (Engeström 2008). Nine years later I undertook a funded 
research study which followed up eight of the respondents from the earlier ethnographic research. Four of the participants were university-based teacher educators and I reinterviewed them about their changing role and experiences of working in teacher education in England over the nine years since the first study (see Douglas 2016). The other participants were four of the pre-service teachers who had undertaken their teaching practice in the research school. The school placement was an eight month extended practicum which constituted their main school experience before undertaking a second and much shorter placement in a second school. This article focuses on the reflections of the pre-service teachers' experiences of learning and how they believe these experiences have influenced their learning in their subsequent careers.

Utilising relatively cost effective and easily manageable follow up studies to enhance conceptual understandings gained from earlier in-depth data analysis after an extended period of time in the field is forwarded as a way to build on small-scale, relatively short-term and predominantly qualitative ethnographic studies. The discussion considers the role of theory in data analysis and suggests a flexible and adaptive design to research studies in order to help develop insights into concepts being researched. Generating data from a systemic focus (teacher education as an activity in a school) to an individual focus (respondents' perceptions of their learning experiences) was undertaken owing to me not revisiting the research field (as the respondents were no longer at the school). Therefore, I utilise insights on the social construction of time as I view the data through a new lens; one which addresses this changed unit of analysis. Not only is the newly generated data analysed through a different perspective but this analysis comments further on the previously analysed data and highlights how concepts taken from Bourdieu and the social construction of time are central to appreciating the learning process. The discussion at the end of this article considers the 
benefits of researching in this adaptive and flexible way when undertaking research in what may be referred to as time-lapse ethnography.

\section{The social construction of time}

The value of considering my data through a new lens comes from questioning the fundamental approach to what I am studying. All generation of data is guided by presupposition. The ethnographic research explored school subject department environments and viewed teacher education as one activity within the settings. In the follow up study, the analysis considers how people speak and reason about their development over time and how they view themselves in relation to their experiences in teaching. It focuses on thoughts and responses to understandings of one's past, present and future. I view both sets of data utilising the insights of authors such as Bourdieu (2000), Mead (1932) and Giddens (1991).

A number of sociologists have written about time as a subjective social category as well as acknowledging its existence as objective and chronological (Bourdieu 2000; Mead 1932; Giddens 1991). Time is believed to be reflectively appropriated by individuals in that it is constructed by an interpretation of their past or possible future in relation to their present (Mead 1932). Mead refers to the 'specious present' which consists of horizons of the past and the future from where we interpret or imagine what has come before and what will happen next. Such temporal horizons are created reflectively and may be helped by a person's recollections of similar past situations. These may then assist interpretations of anticipated futures (Carmo et al. 2014). Such constructions may be changeable based on continual reflection on the possible risks and benefits of decisions and how choices may influence the future. The ability to make plans is conditioned by one's social past and by a 
sense of the security and stability of the present (Bourdieu 2000). Therefore, time may be seen as a socially determined universe in that the relationship individuals maintain with it intersects with a set of social possibilities of an economic and cultural nature (Carmo et al. 2014, 338).

Bourdieu adopts the concept of capital which refers to resources or forms of power that control the definition of what it is to be valued in a field, with the field being a network of social relationships where participants compete in controlling and accruing capital (Bourdieu 1990). In this study, the field can be seen as teaching and career development where different forms of capital exist. These may help those participating in the field succeed in determining their role, whether this be by accruing social capital in order to build networks with other participants, or economic capital which may enable flexibility gained from financial freedoms or cultural capital that may provide access to and knowledge of other cultural institutions, or indeed by developing any combination of the three. Having the appropriate form of capital (that which is highly regarded within the field) creates opportunities for career development.

The research study explores the construction of past and future reflections in relation to participants' responses to questions about their learning to teach and their careers. The linear dimension of professional careers (Roth 1963) considers movement between career levels as periods during which individuals have to accommodate proof of competence in order to move up the career ladder. In Bourdieusian terms, as noted above, this competence is also linked to cultural and social capitals ensuring the reproduction of social order. Focusing on labour markets and employment prospects, positive job outcomes have been defined as being based on the acquisition of resources that make working success viable (Carmo et al. 2014). Modern societies are partially characterised by the capacity to construct open futures with 
employment prospects constructed from subjective orientations and dispositions (Luhmann 1982):

One tries different applications of the skills, talents and other resources which we have, suspect we have or hope to have, attempting to discover which results bring most satisfaction (Leccardi 2005, 141).

Bourdieu refers to the field (such as that of teaching and career development) as a game which offers certain rewards. One's habitus can be seen as 'a system of dispositions attuned to that game' (Bourdieu 1993, 18). The concept of habitus as defined by Bourdieu is 'a set of historical relations 'deposited' within individual bodies in the form of mental and corporeal schemata of perception, appreciation, and action (Bourdieu and Wacquant 1992, 16). Habitus is about the internalisation of social structures and can be considered as participants' disposition. It is possible to explore the notion of habitus by considering the type of capital which transfers from one field to another. This is useful when considering teaching and career development.

\section{The conceptualisation of time and place in this ethnographic study}

Time projections (Carmo et al. 2014) may be considered cumulatively (a strategic process where temporal continuity is established with a potential future relatively open) or noncumulatively (defined as a discontinuity between the past, present and future). This paper explores the perceptions of participants' pasts and futures and considers data on capital acquisition in relation to employment trajectory. 
Hammersley (2006) raises questions of much contemporary ethnographic fieldwork in education with regards to the brevity of time spent in the field, which thereby restricts historical perspectives of both the research settings and the biographies of participants. If long term ethnography aims to reflect on how the passing of time becomes a factor in the analysis of data, and if we are to add the dimension of time to the design of classic ethnographic studies in education, then research needs to track the way that change is differentially experienced and acted upon by individuals. There is a danger that if fieldwork is relatively brief, changes in short or long term patterns may not be detected. This has implications for generalisability as a consequence of changing from an anthropological model of ethnographic fieldwork to its more recent forms; studying elements of people's lives over relatively short time periods (Parker-Jenkins 2016).

Three different ethnographic time modes have been identified which consider the length of time of fieldwork as well as the frequency with which researchers engage in fieldwork (Jeffrey and Troman 2004). Firstly, a compressed time mode acts as a snapshot in time. The other two time modes use longer flexible approaches. The time mode of my original study could be considered as a selective intermittent time mode. I made 80 school visits during one school year adopting a flexible approach as I was increasingly selective about the people with whom I spent time. Thirdly, a recurrent ethnographic time mode consists of temporal phases which formalize the research methodology and is described as more of a documentary approach:

The researcher is able to use the data as a comparison with previous research visits. It may be an opportunity to follow the narrative of an experience such as the development of teachers' and learners' skills over a specific time period and to chart the development tensions and dilemmas of people in the narrative (Jeffrey and Troman 2004, 542). 
This ethnographic time mode is closer to the 2015 research study I describe in this paper.

Longitudinal research studies in education which focus on the experiences of participants are more likely to follow the respondents from the initial field site to other fields. Therefore, longitudinal field work in education may be further complicated by it taking place in new contexts as well as over time. Rahm (2012) for example explores different forms of engagement and identity work in science among a group of first and second generation immigrant girls during a three-year ethnographic study supplemented by individual and focus group interviews of the girls and their instructors. She asks in what ways time constitutes the manner the respondents understand science and how they position themselves within science. She illustrates what it means to engage in science and develop identities in science over time and in different settings. In doing this she challenges traditional ethnographic studies that are locked in time and space. In the study reported here I extend an ethnographic study of learning to teach by interviewing respondents online nine years after the initial research and after the completion of their teacher education course in order to develop insights around the initial research results by focusing on the temporal aspects of data.

With the availability of new technologies new ethnographies have usefully been informed by innovative methods for generating data, changing the need for the researcher to be personally in the field (Parker-Jenkins 2016). In advocating the use of new technologies for locating and engaging past respondents in order to generate new research data through online interviews, I am using the internet as a tool to develop my ethnographic research. This may appear as a sort of straightforward technological development in the method used but there is a 
considerable amount of literature which addresses the methodological and epistemological issues associated with digital ethnography. Many new ethnographic methods have departed from an observational approach to seek to find routes through which the ethnographer might engage with other people. In doing so, they engage with multiple media and methods adapted to specific circumstances and projects (Pink 2011, 274). Social interactions in online environments present a challenge for social researchers and open up a new field for qualitative research (Dominguez et al. 2007). Challenges of mediation, of online settings and shifts in distance and time are considerable. An approach recognising a plural concept of sociality that allows the researcher to focus on the qualities of relatedness in online and offline relationships is offered as a way of understanding how social media practices are implicated in the construction of new data (Postill and Pink 2012, 132).

Opening up the conversation about conceptual and practical underpinnings of traditional and new concepts of educational ethnography (Webster and Marques da Silva 2013, 129) can start to address the potential of longitudinal studies of a qualitative nature to highlight interconnections between different spheres and phases of life. Questions about the most appropriate conceptualisations of learning, teaching and education for example, are of enormous significance for policy and practice in education. Qualitative research work can enrich the understanding of the nature of social change and lived experience. Multi-sited ethnography and longitudinal studies make possible travel over extended periods of time and can attempt to unpack connections and barriers in learning across practices (Marcus 2009). Tracking change in relation to original theoretical related aims aids analytic progression but this is in tension with generating emergent theories based on participants' perspectives (Pollard 2007, 4). When writing about the evolution of what is considered to be the earliest UK longitudinal ethnography in the field of education, Pollard (2007) comments 
on 'principled pragmatism' as being needed when considering methodological principles and theoretical conceptualisation. His research tracked the learning, identity and pupil careers of two cohorts of children from very different socio-economic communities over 12 years. This article too proposes a form of principled pragmatism in adapting theoretically informed data generation in order to aid analytic progression. It does this by focusing on the temporal aspects of the data content.

\section{The research study}

The original ethnographic research (a year-long study based in one secondary school undertaken in 2006) interviewed each pre-service teacher twice and observed them working with mentors and university tutors in the school setting (Douglas 2014). Four of the preservice teachers were then interviewed for this follow up study in 2015. The initial research explored the experiences of pre-service teachers working in school subject departments when on their teaching practice. The study questioned how the departments contributed to the preservice teachers' learning. The current study, through in-depth interviews, explores responses from the past respondents in relation to questions about their learning to teach and their subsequent careers in the nine years since the first study. The data illustrated here focus on how pre-service teachers spoke about their learning and how they felt this has influenced their careers. The data analysis in the follow up study uses a social construction of time lens through which to view the data. The data analysis is at the local level and is exploratory of individuals in their particular social context. Insights from the analytical framework are considered alongside data interpretation from the original ethnography as a way of commenting on the earlier results. 
The interviews were semi-structured, qualitative and designed to find out what respondents thought about their experiences of learning to teach, and how these had developed over time. Interviews with the participants were an effective way of exploring their ideas. In focusing on understandings rather than checking accuracy of accounts, interviews were also an appropriate way of exploring the conceptual position taken by respondents with regards to their learning and their careers. The two research questions asked were as follows:

1. How did your experience of learning to teach affect your continued learning and your subsequent career?

2. Have your opportunities to learn changed since taking the teaching course?

Each interview lasted approximately an hour and they were recorded and transcribed verbatim. Prior to the interviews I sent the respondents an in depth account of the first ethnographic study in the form of a published research monograph (Douglas 2014). I highlighted the sections with particular relevance to pre-service teachers' learning opportunities and each respondent agreed to read these as well as the chapter based on the subject department within which they had worked in the school. My aim was to revisit the respondents after a considerable period of time and record experienced consequences in order to gain some further understanding of their reflections on their learning to teach. I therefore considered the four respondents as case studies tracked in relation to the data initially generated in the year-long ethnography.

I located the individuals through social media and the interviews took place using Skype computer software. In the interviews the participants reflected upon their understanding of the process of learning to teach. I had a background history of the development of each 
respondent's learning opportunities in their first school teaching practice on which I could draw as new considerations arose in the descriptive overview of the respondents' case studies. The research monograph acted as a way of revisiting the memories of the respondents' first school teaching experience. However, in reading my book they were also made aware of my interpretations of their learning opportunities when on the teaching course. This was discussed early in the interviews after their initial explanations of how their careers had developed over the years since the course and since their last interview with me. A semistructured and flexible interview strategy was adopted in order to create a guided conversation to elicit rich and detailed information for qualitative analysis. However, I agree with Pollard that it is recognised that 'perhaps in longitudinal qualitative work, analysis is always a provisional form of 'making sense' $(2007,12)$ as qualitative analysis simply provides an illustration rather than generating new forms of representation and analysis of the social world. As interview consent was agreed after each respondent had read the monograph reporting the research in which they had previously participated, I was satisfied that they understood and were happy with my ethical approach to research work. More trusting relationships with better data being produced when participants feel confident in their engagement in research can be seen as a key foundation for a longitudinal approach to ethnography (Pollard 2007, 13).

The objective of the analysis is not to categorise individual teachers and their strategies but to explore the different ways the teachers speak about and make sense of their pasts and futures. In order to offer a vivid picture of the orientations discerned I present several quotations from the data. The interview situation no doubt affected the accounts of the teachers' pasts and futures in as much as what is a socially justified and acceptable way of describing their work experiences and views. However, given my 
own location as an ex teacher turned researcher with past and present experiences in educational settings I tried to maintain a continued level of reflexivity as to how the teachers' identifications and experiences influenced interpretations.

\section{Results}

I select data initially from the interviews in the 2006 study and then from the follow up interviews in 2015. Owing to the word limit of the journal article I shall focus on just two of the participants in the study in order to illustrate how the generated interview data answer the research questions and how the analysis further comments on previous results from the earlier ethnographic study. Both respondents had successfully completed their teacher education course and had qualified as teachers after an initial probationary period in post. The following pen portraits outline their careers to date:

\section{Danni}

After completing her teaching course, Danni worked in a state school for three days, increasing to four days a week for four years. She took on subject leader responsibilities during this time and moved on to full time teaching for a further four years. At the time of interview she had just resigned from her post in order to become a subject leader full time in an independent boarding and day school.

\section{Lauren}


After completing her teaching course, Lauren taught full time for a year in a state school and qualified as a teacher before continuing work at the same school on and off as a supply teacher for a further two years in between travelling. She then taught overseas for two years before undertaking a Masters course in the UK. At the time of interview she was working as a project manager within the healthcare sector.

\section{Interview data from the 2006 study}

In conceptualising the future during the teacher training course particular concerns were at the fore for the respondents. Danni understood the desirability of her learning independently for her future development and welcomed a diversity of ideas from those she worked with, recognising that these will be influenced by her own experiences in education (her 'model'):

My priorities are going to be shaped by everything I am learning. So it is fitting in to my model of what education is. My model is changing. It's not that there wasn't one to begin with; it's just that I had to learn everything because I didn't know anything. As a teaching assistant before I might have thought you are not very good are you, but actually they (the teachers) are. They are working it through with the class. But what I have seen before has informed me as well.

Bearing in mind the insights provided by time sociology frameworks, the above reflection indicates an experience of liminality (a transitional process occupying a position at both sides of a threshold) in which the pre-service teacher understands herself as belonging to a 'now' and a 'then' and also being located in a linear time structure. She goes on to verbalise her concerns looking towards the future as well as looking back at the immediate past: 
It's like my whole life's before me. It's been a huge personal learning curve about what I am like and how I react and oh it's just massive, and what I think about state education. These sleepless nights after talking to [the university tutor] about whether I was going to get a state or private job; I have had to re-think everything. It has changed me dramatically about everything. And I also struggle hugely with what I am doing to my children by doing this. So at the end of last term I was on the verge of giving up because [child name's] report was so bad.

Danni's excitement in feeling 'my whole life's before me' is tempered by her parental concerns of neglecting her children because of the demands of the teacher education course. This reflexivity is rooted in the past as far as what is expected of Danni as a mother. She denies the time to her children in order to invest in her professional career. As seen later, this proves to be an ongoing dilemma for Danni.

Unlike Danni, Lauren finds teachers' differing opinions challenging. Her past successful experiences of teaching overseas make her question why she is finding lesson planning and classroom discipline so difficult in her teacher education course:

I think I was very naive when I started out because I have done quite a lot of teaching beforehand, having been an assistant in Austria and also I taught English in summer schools etc. with quite big classes but because it has never been any prolonged teaching, I've never had to deal with the discipline side of things so much, so with me I am finding I am really struggling with the discipline side. 
Although constantly reassuring herself that the future will not be so difficult Lauren questions her self-motivation finding that 'everything is just so hard'. The monotony she experiences throws into doubt her intention to be a teacher:

I think I am not sure I am going to be a teacher after this because I think to myself, I don't know how I am going to motivate myself all the time. If things don't get much easier in terms of planning lessons, I just feel like I am always under such close scrutiny, and I know that it is not going to be like that next year. But there are still elements that are not clicking or falling into place. I know they will do. I know it will be different next year because not every lesson will have to be all singing and all dancing. And hopefully, once I get into that kind of more realistic teaching routine, things will get easier, but as it is at the moment, I just find that everything is just so hard. The cycle is so monotonous.

In Araujo's (2005) study of $\mathrm{PhD}$ students she describes their time experiences as located in a luminal time and space: 'a suspended now' (201). The present is permanently invaded by the idea of being on the other side qualified as a doctor (or in my research study as a teacher) which will be good. The critical date in the future affects ordinary decisions so that time seems to be frozen. Therefore, the future is determined by the inherent uncertainty of the process where other worries are interrelated. This is apparent in Lauren's interview data from 2006. The future is deeply constitutive of her present. It is a time completely occupied by the teaching certificate. Araujo characterises the study of a $\mathrm{PhD}$ as a phase which signals a permanent experience of transition with students' lives marked by a process of changing and becoming. Both time representation and experience are structured on the basis of reflexivity towards past and future from the position of an 'extended present' (Novotny 
1989). The teacher education course too is characterised as extended time in which for the pre-service teachers the future is continually in the present as anticipation:

I hope to already have in place the skills and experience for my next placement so I will know more of what it will be like to go in as a newly qualified teacher rather than taking a plunge and being completely ignorant. I would like to think I am better at putting on the angry facade. I hope to improve without getting a squashed ego. I tend to want people to like me. But I have to be mean sometimes (Lauren).

The teacher education course is seen as a 'now' with an uncertain outcome and the preservice teachers project the present into the future and focus on a particular kind of future which is lived through the present, but despite the uncertainty the pre-service teachers continue to designate the future as somewhat external:

How realistic and valuable are the university suggestions? If we lived in an ideal world, great, and it would be useful. But it just isn't in the real world. I think you need to recognise that and move on (Lauren).

\section{Interview data from the 2015 study}

In the 2015 interview data, the two pre-service teachers show different temporal perspectives in relation to their past, future and present career trajectories. Danni's current work situation is seen below to be governed through recourse to a highly managerial and accountable discourse: 
You have in your lessons the whole time students who are feeding back on you. There is student feedback at the end of the year and mine is always positive and it's lovely and they are charming but I still think that actually I have watched colleagues and that has been used against them. If a student doesn't like a teacher there's no help given and in fact they'll (senior management) use it as a stick to beat you. I found that constant observation very difficult.

Danni compares her learning opportunities in her current post with those when she was training to teach. Although aware of her trepidation at receiving criticism when on the teaching course, this had come with support and detailed discussion on her personal growth ('comments were supportive and critical but not nastily so') unlike the nastiness evident in the hierarchical relationships described above in her current school.

For Danni, some of her worries as a mother concerned for the education of her children are addressed by her learning to teach:

My eldest son struggled in primary school which is why he ended up in the private system. They wanted to statement him, and I really had to change the way I thought because I had been brought up with academic success is the most important thing but then going to [the University] and I can remember the lecture but I cannot remember who gave it, and they didn't use this phrase but 'you're not born with set intelligence'.

The teacher education course and her subsequent experiences of teaching reinforce Danni's developing understanding of how one learns. She is helped in understanding this through her experience of anxiety, which permeates her own learning as a novice teacher and her undertaking of the maternal role. Appreciating how this develops over time (from starting 
the course to teaching in schools alongside the educational development of her children) enriches an understanding of her reflections on the past, present and future.

Danni planned her career steps and viewed her employment in teaching as controllable accruing cultural capital in order to gain promotional opportunities in her teaching career. Such an orientation to her future could be seen as cumulative and 'scheduled' (Ylijoki 2010). A scheduled future treats employment as if it is predictable and the future orientation is individualistic. Danni therefore controls her scheduled future with specific aims, and plans for her career steps exhibiting habitus as 'a system of dispositions' attuned to the game or field of teacher employment (Bourdieu 1993, 18). In data generated from the interviews with Lauren, anxiety in relation to her understanding of the process of learning to teach is also expressed throughout her teaching career. However, Lauren's future orientation could be described as non-cumulative and 'multiple'. A multiple futures orientation consists of 'speculating, imagining and constructing a diversity of futures, including alternative careers' (Ylijoki 2010, 377). For this it is necessary to be adaptable and opportunistic in pursuing a variety of work routes with the acquisition of different forms of capital both social and economic. Consequently, those relying on this orientation 'are only loosely embedded in the present' (379). This is evident in Lauren's interview data:

I did feel that I was not really learning very much as a teacher and I wasn't really gaining enough in life experiences if that makes sense which is why I decided to move to Italy and acquire a completely different lifestyle. So I was there for probably about a year and I was teaching English out there as well on a very ad hoc basis. And after that I went to Turkmenistan with a similar mentality of wanting to explore life experiences. I then started my Masters in Educational Planning, Economics and International Development. Now I am working as a project manager focused on executive level posts within the third 
sector. It's not my ideal job. But it's still a job which is good because studies take a lot of your financial resources and opportunity costs. So I am glad to have a job which is still related to development and has a socially productive direction and still pays money.

In reflecting on how her learning to teach has enabled her desire to follow a socially productive career Lauren questions how the past contributed to shaping her future:

I think the University could have done more to go through lesson planning in a more methodical way. I don't know even if they had told me that this is necessary in a didactic way, I don't know that I would have been able to absorb it in such a way. We hadn't really had a clear idea of how to deliver segments of a lesson but I don't know to what extent that would have helped me then. I am contradicting myself to an extent saying that that would have been helpful but the flip side of that is that yes it probably would have been helpful but would I have been in a position to absorb this information? I don't know. I want to develop my own personal knowledge and my personal experiences etc. Part of that is learning more and as a teacher of languages in particular I don't know if there is that much you end up learning on a day to day basis. I still do have the desire to pursue a socially productive career.

Lauren doubts that her suggestions for her preferred way of learning in the teacher education course would have actually benefited her learning to teach. She feels that she needed time to absorb the learning process. This became a priority for her professional and personal development which she put before developing her teaching career. Lauren's habitus is moulded by her desire to gain 'life experience'. The opportunity for further study enables her to feel that she could still follow a 'socially productive career' and encourages her to change her network of social relationships (her field). 
When writing on temporality and biography, Leccardi (2005) notes that gaining in importance are biographical models increasingly distant from linear trajectories of life characterised by strong individualisation and at the same time by an accentuation of risky traits (125). Medium and long term plans of action which influence everyday life can be replaced with guidelines: a compass for action which is not binding from the standpoint of measurable results, where small projects are designed on shorter temporal scales (130). These are easy to reverse and transform as life is no longer planned along a line that stretches from the past into the future. Instead decisions are taken from time to time according to situational and contextual needs and desires (Rosa 2005, 19). This way of constructing biography is more and more widespread especially among those who possess high levels of education (one example of cultural capital).

\section{Discussion}

The teacher education activity systems identified in the two school departments where the participants in this article initially worked highlighted the learning opportunities for preservice teachers when working within them. However, this was only a partial exploration of how the pre-service teachers learnt as part of their teacher education course. In the follow up study, the respondents' interpretations of their pasts are made in the 'specious present' (Mead 1932) and are created reflectively. They appear to be helped in their future ideas by the recollections of similar past situations: Danni's search for a supportive learning environment which does not entertain 'set intelligence'; Lauren's wish to develop a socially productive career whilst pursuing new life experiences. Their anticipated futures (Carmo et al. 2014) are constructed by continual reflection on the possible risks and benefits of their decisions. 
These are determined by a set of social possibilities which are of an economic and cultural nature (Bourdieu 2000). Both respondents' educational capital gives them the ability to make plans. Conditioned by their social past and by a sense of the security and stability of the present (Lauren has to work to pay for trying alternative and multiple futures: 'it's not my ideal job') they focus on future orientations. A third future orientation identified in research on episodic labour is named as 'instant living' which concentrates on the present (Ylijoki 2010). This orientation does not think about the future at all but time is 'perceived as nonlinear and fragmented into separate instants and episodes without constructing coherency’ (376). Individuals do not plan a future as they see it as beyond their control often owing to a lack of acquired capital. However, although Danni and Lauren differ in their cumulative and non-cumulative time projections (Carmo et al. 2014) time as a sociological variable is actively controlled.

One aim of this article is to forward a methodological approach in which analytical case studies of follow up interviews are conducted in order to enhance an ethnographic account (Jacobsen 2014, 47). The value of the interviews add analytical depth and complexity to the understanding of the phenomenon in question: learning to teach. Utilising an analytic process informed by ideas from the social construction of time aims to add to the understanding of the possibilities of a follow up interview informed approach to an ethnographical study of teacher learning.

\section{Concluding points}

With the intention to move beyond revisiting familiar research ground (Tatto, Richmond and Andrews 2016) and re-generating data in a similar manner to earlier studies but using 
contemporary situations to explore the same research questions initially asked, this research study develops the focus of the original ethnographic research work by following up research participants after a period of time. Such work can start to answer the call to develop 'new techniques of qualitative longitudinal research to enrich and challenge more established quantitative longitudinal resources' (Pollard 2007, 16). Although interview-only case studies can claim only intrinsic validity, the investigation of the processes of change presents a significantly different picture from the dynamics of more traditional research in teacher education which often emphasises descriptive analysis (Douglas 2014). This cannot address such concepts as habitus which is not a consciously created way of working but is individually constructed of past experiences, and may develop with regards to career development if opportunities for working in numerous activities have been experienced (as seen in the examples of Danni and Lauren). Each field is constructed differently and therefore the opportunity to bring relevant capital from one field to another can be limited. Rules for accruing relevant capital cannot be written down specifically, as these vary within and between fields and therefore one needs to learn how to understand the field whilst working within it over time.

Combining interviews undertaken after a considerable period of time as an important evidentiary base to sit alongside previous participant observation, points to extended possibilities of allowing interview-only studies and ethnography to enrich one another. Sharing the researcher's interpretation of data from an initial project was undertaken by disseminating results in the form of a research monograph. More commonly a short research report may be sent to interested participants after a study has concluded but rarely would a detailed analysis of an ethnographic project be shared with its participants some time after the research was undertaken and then used as a way of following up the initial study. In future 
ethnographic work consent for follow up interview-only studies could be agreed in advance especially as returning to the field after a considerable lapse in time is unlikely in educational ethnography where people rarely remain in the same place. Accepting that an interview-only study is not in itself ethnography, such follow up projects are easily administered and undertaken with the advent of cheap and accessible technology. This is not especially time consuming or difficult to do particularly if using social media to locate respondents and Skype software to conduct interviews. This form of methodological endeavour can start to contribute to answering the demand for longitudinal qualitative work in education.

\section{References}

Araujo, E. 2005. Understanding the $\mathrm{PhD}$ as a phase in time. Time and Society 14, no. 2/3: 191-211.

Bourdieu, P. 1990. The Logic of Practice. Cambridge: Polity.

Bourdieu, P. 1993. Sociology in Question. London: Sage.

Bourdieu, P. 2000. Pascalian Meditations. Cambridge: Polity.

Bourdieu, P. and Wacquant, L. 1992. An Invitation to Reflexive Sociology. Chicago: University of Chicago Press.

Carmo, R.M., Cantante, F. and Alves, N de A. 2014. Time projections: youth and precarious employment. Time and Society 23, no. 3: 337-357. 
Dominguez, D., Beaulieu, A., Estalella, A., Gomez, E., Schnettler, B. and Read, R. 2007. Virtual ethnography. Forum: Qualitative Social Research 8, no. 3: 1-4.

Douglas, A.S. 2011. Learning on the job: A cultural historical activity theory approach to initial teacher education across four secondary school subjects. Ethnography and Education 6, no. 2: 195-211.

Douglas, A.S. 2014. Student Teachers in School Practice: An analysis of learning opportunities. London: Palgrave Macmillan.

Douglas, A.S. 2016. Extending the teacher educator role: Developing tools for working with school mentors. Professional Development in Education DOI:

$10.1080 / 19415357.2016 .1258655$

Engeström, Y. 2008. From Teams to Knots: Activity-theoretical studies of collaboration and learning at work. Cambridge: Cambridge University Press.

Giddens, A. 1991. Modernity and Self-identity: Self and society in the late modern age. Oxford: Polity.

Glaser. B. and Strauss, A. 1967. The Discovery of Grounded Theory. Chicago: Aldine. Hammersley, M. 2006. Ethnography: Problems and prospects. Ethnography and Education 1, no. 1: 3-14. 
Jacobsen, A.J. 2014. Vignettes of interviews to enhance an ethnographic account.

Ethnography and Education 9, no. 1: 35-50.

Jeffrey, B. and Troman, G. 2004. Time for Ethnography. British Educational Research Journal 30, no. 4: 535-548.

Leccardi, C. 2005. Facing uncertainty: Temporality and biographies in the new century. Young: Nordic Journal of Youth Research 13, no. 2: 123-146.

Luhmann, N. 1993. Risk: A Sociological Theory. Berlin, NY: Walter de Gruyter.

Marcus, G.E. 2009. Multi-sited ethnography: notes and queries. In Multi-sited ethnography: Theory, praxis, and locality in contemporary research, ed. M. A. Falzon, 181-196. Burlington, VA: Ashgate.

Mead, H. 1932. The Philosophy of the Present. Chicago: University of Chicago Press.

Novotny, H. 1989. Mind, technologies and collective time consciousness: From the future to the extended present. In Time and Mind: The Study of Time, ed. J.F. Frasier, 197-204. Madison, WI: International University Press.

Parker-Jenkins, M. 2016. Problematising ethnography and case study: Reflections on using ethnographic techniques and researcher positioning. Ethnography and Education, DOI: $10.1080 / 17457823.2016 .1253028$ 
Pink, S. 2011. Mutimodality, multisensoriality and ethnographic knowing: Social semiotics and the phenomenology of perception. Qualitative Research 11, no. 3: 261-276.

Pollard, A. 2007. The identity and learning programme: 'principled pragmatism' in a 12-year longitudinal ethnography. Ethnography and Education 2, no. 1: 1-19.

Postill, J. and Pink, S. 2012. Social media ethnography: The digital researcher in a messy web. Media International Australia 145: 123-134.

Rahm, J. 2012. Collaborative imaginaries and multi-sited ethnography: space-time dimensions of engagement in an afterschool science programme for girls. Ethnography and Education 7, no. 2: 247-264.

Rosa. H. 2005. Social acceleration: Ethical and political consequences of a desynchronised high speed society. Constellations. 10, no. 1: 3-33

Roth, J. 1963. Timetables: Structuring the Passage of Time in Hospital Treatment and Other Careers. New York: Library of Congress.

Tatto M., G. Richmond, and D. Andrews. 2016. The research we need in teacher education. Journal of Teacher Education 67, no. 4: 247-250.

Walford, G., and A. Massey. 1998. Children Learning in Context. London: JAI Press. 
Webster, J., and S. Marques da Silva. 2013. Doing educational ethnography in an online world: Methodological challenges, choices and innovations. Ethnography and Education. 8, no, 2: 123-130.

Ylijoki, O-H. 2010. Future orientations in episodic labour: Short-term academics as a case in point. Time and Society 19, no. 3: 365-386. 